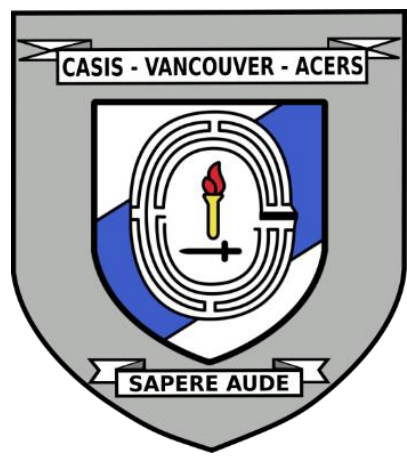

\title{
SOCIAL COHESION AND CONFLICT DYNAMICS ON SOCIAL MEDIA
}

Date: May 20, 2021

Disclaimer: This briefing note contains the encapsulation of views presented by the speaker and does not exclusively represent the views of the Canadian Association for Security and Intelligence Studies.

\section{KEY EVENTS}

On May 20, 2021, the Canadian Association for Security and Intelligence Studies (CASIS) Vancouver hosted a digital roundtable where Dr. Lisa Schirch, Senior Research Fellow and Social Media, Technology and Peacebuilding Programme Director at the Toda Peace Institute, presented on Social Cohesion and Conflict Dynamics on Social Media. The presentation was followed by a question-andanswer period with questions from the audience and CASIS Vancouver executives.

\section{NATURE OF DISCUSSION}

\section{Presentation}

Dr. Lisa Schirch's presentation was based on the book, Social Media Impacts on Conflict and Democracy, which she contributed to and edited. Dr. Schirch began by discussing shifting beliefs about the impact that social media can have. Dr. Schirch then highlighted how social media can be a tool for the dissemination of disinformation and offered some real-world examples. Additionally, some collective and individual steps that can be taken to combat disinformation on social media were presented.

\section{Question and Answer Period}

The question-and-answer period involved a discussion of the use of social media by Generation $Z$ and its potential impact on the Israel-Palestine conflict. Further, Dr. Schirch addressed the issue of balancing free speech and online censorship, along with what different social media platforms are doing to find this balance. She also discussed the potential repercussions involved in taking legal recourse against those who spread hate speech and disinformation online. 


\section{BACKGROUND}

\section{Presentation}

Often in security and intelligence, cybersecurity and cyberattacks are seen as the primary focus of concern. However, the unique problem that social media presents needs greater attention because it is shifting governmental systems, increasing violent extremism, and polarizing populations around the world. The book, Social Media Impacts on Conflict and Democracy addresses this research gap by presenting the findings from 13 different case studies in Latin America, Africa, Asia, and Northern Ireland on the local impacts of social media. In these case studies, researchers considered how disinformation on social media can be polarizing and spread violent extremism.

Opinions on the impact of social media have shifted in comparison to ten years ago. In 2011, people were excited about social media and believed that it would be used as a tool to strengthen democracy and freedom around the world. During the Arab Spring, in Egypt and other countries, Facebook and Twitter were used as a non-violent means for social change. However, it was soon recognized that ISIS was using social media and other online platforms very effectively to convey its messaging through viral videos and other media platforms. There was a quick transition from techno-optimism towards techno-pessimism. This harnessing of social media for nefarious purposes is now called the weaponization of social media. Think tanks, namely Freedom House, have recognized the impact of social media on the rise of extremism and the decline of democratic freedoms around the world.

Some examples of the negative impact social media may have include the influence of social media on the 2016 US election and the Rohingya genocide in Myanmar. The Reuters report called Hatebook details the way that the Myanmar military used Facebook to promote hatred and genocidal violence against Muslim Rohingya people (Stecklow, 2018). During this time, the ability for disinformation on social media to distort people's understanding of basic facts and to increase polarization began to be recognized. Instead of terminology such as "fake news" and "junk news", Social Media Impacts on Conflict and Democracy refers to the current social media environment as having "information disorders". These disorders disrupt the cycle between quality information, democracy, and social cohesion, possibly resulting in authoritarianism and polarization. 
Social media platforms, such as Facebook, Twitter, and WhatsApp, offer their users a free service; yet they are extremely profitable. They make billions of dollars from advertising because they allow advertisers to access extensive data to identify potential buyers much more specifically than legacy media (cable news, magazines, radio, etc.). Facebook and other similar companies have access to a large amount of data regarding their users' online activity. They can predict what products people may want to buy and their algorithms will show users what they are most likely to be interested in. In policy circles, this is a big discussion because users essentially agree to be surveilled when they sign Facebook's privacy agreement. There is no option to not be surveilled. Even people who do not have Facebook accounts may be tracked through other activities that they carry out on the internet through third parties sharing their data with Facebook. This data collection profit model has been described by Harvard scholar Shoshana Zuboff (2019) as "surveillance capitalism."

The longer someone spends on a particular online platform the more money that company can make through advertising. For example, Facebook may use algorithms to show people what they think they will like to try to keep them on their platform. Human brains are wired to hone in on things that they already agree with, so these algorithms tend to show things that will tend to reinforce people's beliefs. This can have the consequence of creating echo chambers with no dissenting opinions which leads to polarization and increasingly extreme views - even when the information being viewed and shared is false. In 2018, MIT researchers found that disinformation travels six times as fast as truth on social media, including things like conspiracy theories (Vosoughi et al., 2018). Consequently, information that reinforces our political beliefs and induces an emotional response spreads quicker. For example, there has been a great deal of disinformation spread online about COVID-19 and vaccine information.

There are many organizations working against the spread of extremism online and the 'hate-for-profit' model that many social media corporations benefit from. Some of these organizations try to expose extremist content left on Facebook for long periods of time, including terror groups and white supremacist content. There has been a growing conversation about why this information is not being taken down. Leaders of large social media companies have been brought before the U.S. Congress to answer to this. Currently, Facebook and other platforms are not held liable for the content posted on their platforms and cannot be sued for it. This means that everyone has total speech freedom on free-to-use social media platforms including malicious actors. This speech has contributed to polarization, large-scale violence, and political instability around the world. 
However, social media can contribute to social cohesion, increased democratic participation, and more citizen engagement. In some countries, such as India and Pakistan, civil societies are using social media to send positive messages to facilitate the de-escalation of tensions. In Canada, some peace-building groups have been focusing on how to teach digital media literacy and raise awareness of digital polarization from an early age. There are also groups building online tools geared towards predicting conflict and warning against hate speech on social media. A multilateral approach is still necessary to reduce cyber conflict and disinformation, one in which tech companies, civil society, and government engage to facilitate digital peacebuilding.

\section{Question and Answer Period}

The question-and-answer period began with a question about the use of social media by Generation $\mathrm{Z}$ in the Israel-Palestine conflict. Dr. Shirch stated that social media and online platforms have a place in contributing to the peacebuilding process in the Israel-Palestine conflict and there are some groups in the region that are creating some cross-community dialogue on the internet. However, for any sort of lasting positive change to occur, it will require more than a movement on social media. It will take leaders from both sides to come to the table and negotiate an outcome that will lead to more justice.

The conversation then moved to the issue of censorship online. Dr. Shirch insisted that finding the right balance between online censorship and removing hate speech remains a dilemma. There are groups and NGOs that are trying to flesh out exactly what dangerous speech looks like. This includes speech like direct threats or directing and planning for violence. Many people are firm believers in freedom of speech, and social media challenges this belief. The principle that one challenges hate speech with more speech does not seem to work on social media, because disinformation and hate speech travels six times faster on social media than the truth does (Vosoughi et al., 2018). It also brings the issue of what kinds of powers do companies like Facebook and Twitter have to limit speech? And under whose authority? Many extensive conversations at the highest level are being held on these subjects, but at the moment there is no quick answer as to why.

Moreover, there is no financial incentive for companies like Facebook and Twitter to comprehensively address hate speech on their platforms and contribute towards creating greater social cohesion. However not perfect, Twitter has been more responsive than Facebook in this area. It may come down to government action to create change in this instance. Germany has created the most robust 
legislation in this regard, requiring social media companies to remove extremist content or face financial penalties. There are issues, however, with finding enough people to monitor and remove all of the extremist content that is posted on social media. Additionally, combing through extreme and disturbing content all day has caused mental health problems for many of these employees. Other suggestions involve creating risk audits where social media companies will be assessed on how much of a risk they pose to society and democratic institutions and will need to be insured accordingly.

These companies became dangerous far quicker than any government was able to keep up with legislatively. However, the Canadian government has some great ideas when it comes to addressing online extremism and labeled the Proud Boys a terrorist group much quicker than the US. Likewise, Vancouver's tech sector may be able to contribute to this as well.

\section{KEY POINTS OF DISCUSSION}

\section{Presentation}

- The unique problems that social media presents requires greater attention because it is shifting governmental systems, increasing violent extremism, and polarizing populations around the world.

- Opinions of social media have quickly moved from techno-optimism towards techno-pessimism and a recognition of the weaponization of social media.

- Surveillance capitalism is the profit model of social media companies, and they use algorithms to show people content they agree with to keep them on their platforms creating echo chambers.

- Disinformation travels six times as fast as the truth on social media and this has contributed to damaging democracy and violence (Vosoughi et al., 2018).

- Social media can also be used to promote social cohesion and positive change.

\section{Question and Answer Period}

- Social media and online platforms can contribute to peace in the Middle East, but it is not enough to resolve the situation.

- The right balance between freedom of speech and censorship is still being debated extensively throughout the world and there is no easy solution to this debate.

- Social media companies do not currently have much incentive to facilitate social cohesion and it may take government action to resolve this situation.

The Journal of Intelligence, Conflict, and Warfare

Volume 4, Issue 2 
- The Canadian government has some good ideas as to how to facilitate social cohesion on the internet.

- There is a research gap in determining if certain social media platforms are better for social cohesion than others, such as Twitter, which has shown to be better than Facebook in this regard. 


\section{References:}

Stecklow, S. (2018, August 15). Hatebook. Reuters.

https://www.reuters.com/investigates/special-report/myanmar-facebookhate/

Vosoughi, S., Roy, D., \& Aral, S. (2018, March). The spread of true and false news online. Science (American Association for the Advancement of Science), 359(6380), 1146-1151.

https://doi.org/10.1126/science.aap9559

Zuboff, S. (2019, January 15). The age of surveillance capitalism: The fight for a human future at the new frontier of power. Profile Books.

\section{(c) $(7) \ominus$}

Commercial-NoDerivatives 4.0 International License.

(C) (LISA SCHIRCH, 2021)

Published by the Journal of Intelligence, Conflict, and Warfare and Simon Fraser University

Available from: https://jicw.org/

The Journal of Intelligence, Conflict, and Warfare Volume 4, Issue 2 